\title{
Numerical analysis on stress and displacement of tapered cantilever castellated steel beam with circular openings
}

\author{
Taufiq Ilham Maulana ${ }^{1, *}$, Hakas Prayuda ${ }^{1}$, Bagus Soebandono ${ }^{1}$, Martyana Dwi Cahyati ${ }^{1}$, \\ and Eva Hanifatu Zahra ${ }^{1}$ \\ ${ }^{1}$ Department of Civil Engineering, Faculty of Engineering, Universitas Muhammadiyah Yogyakarta, \\ 55183, Lingkar Selatan Street Tamantirto Kasihan Bantul Yogyakarta, Indonesia
}

\begin{abstract}
Castellated steel beams are made from normal steel beams cut into half with certain pattern and re-jointed to increase its height. This action results in many shapes of openings in its web, one of them being circular. Circular openings of castellated beams can also be implemented with single fix supported structures, but if uniform shape is used, it will reduce its effectiveness. In this paper, adoption of tapered shape on castellated beams with circular openings as cantilever structures will be discussed. This study uses $150 \times 75 \times 5 \times 7$ and $200 \times 100 \times 5.5 \times 8$ IWF sections with variations of opening diameters, opening spaces, and span lengths. The steel has a yield strength of $400 \mathrm{MPa}$ and the analysis runs with solid element 10-node tetrahedron using the finite element method, by observing Von Mises stress and displacement. Free-licenced software such as LISAFEA 8.0 and FreeCAD are utilized for analysing and drawing solid elements. The result shows that the optimum height of IWF section for $150 \times 75 \times 5 \times 7$ is $230 \mathrm{~mm}$ and for $200 \times 100 \times 5.5 \times 8$ is $318 \mathrm{~mm}$ between span lengths of $2 \mathrm{~m}$ to $3.5 \mathrm{~m}$. It can be concluded that each of the span lengths has various optimum diameters and opening spaces to acquire the smallest stress and displacement.
\end{abstract}

\section{Introduction}

Cantilever beams are one among many types of beams which mainly support shear and flexural loads. Cantilever beams are held by a fixed support in one side and is freesupported at the other side. This kind of structure can be made from any material. Nowadays, many buildings use cantilever beams in its construction, and are commonly made from steel, reinforced concrete, woods, aluminium, and other materials. In some developing countries, cantilever steel beams are favoured because of their advantages, namely the assured strength quality resulting from factory production, their high strength compared to other materials, and the speed of installation. Despite its evident benefits, steel usage can still be optimized, especially in cantilever beam structures.

\footnotetext{
${ }^{*}$ Corresponding author: taufiq.im@ft.umy.ac.id
} 
Many researchers have studied about how to refine the usage of steel in beams. Many studies have been conducted by making the steel beam castellated [1-4]. Castellated steel beams are a type of beam made by reforming the shape of the steel beam's section into a half with a particular pattern and by reconnecting those parts into a new steel beam. This doubles the steel beam's moment of inertia while maintaining the same volume [5]. The shape of web openings can also be variated, depending on its function and aesthetic considerations. Shapes existing currently are circular [6], cellular [7], or even sinusoidal shapes [8].

In another study about beams, cantilever beams are made by forming the beam with a tapered shape [9-12]. Since the cantilever beam is only held by one support, the internal bending and shear force resulting from the given load will only be focused near the support while no reaction is felt by the free support. Because of this condition, the tapered shape will be very optimum for cantilever beams.

However, only few studies have been done about castellated beams implemented as cantilever beams [13]. Furthermore, the fusion between the implementation of castellated beams and the tapered shape in cantilever beams has not been done before, especially for circular openings. In this research, a tapered beam will be adopted on castellated beams in cantilever supported conditions. In addition, it was decided to implement circular openings in the samples. Several numerical analyses under linear material conditions and uniform static gravitational loads were performed to determine the stress and displacement among the variated opening spaces, diameters, and section types of tapered cantilever castellated beams for several span lengths. From this research, the result is expected to provide new options to practical users in the field, especially for constructors and designers of buildings, regarding how to use steel more wisely.

\section{Samples and analysis method}

The number of samples depends on the chosen variations. The variation is considered based on two IWF sections that are commonly used for buildings, as well as span lengths, opening diameters and opening spaces that are suitable for the related IWF section. All chosen variations are provided in Table 1. After all models for the samples were made, a convergence test was performed to determine the amount of mesh in finite element analysis that can be used. Then, all samples were analysed through a numerical analysis using LisaFEA software which can simulate linear conditions with a solid element 10-node tetrahedron. All of the samples with the same span length were given the same static load. In the end, Von Mises stress and displacement were generated from LisaFEA and compared to each other.

Table 1. All variations of tapered cantilever castellated beam used.

\begin{tabular}{|c|c|c|c|}
\hline IWF Section & $\begin{array}{c}\text { Span Length } \\
(\mathbf{m})\end{array}$ & $\begin{array}{c}\text { Openings diameter } \\
(\mathbf{m m})\end{array}$ & $\begin{array}{c}\text { Openings space } \\
(\mathbf{m m})\end{array}$ \\
\hline $150 \times 75 \times 5 \times 7$ & 2 & 60 & 40 \\
\hline $200 \times 100 \times 5.5 \times 8$ & 2.5 & 70 & 45 \\
\hline & 3 & 80 & 50 \\
\cline { 2 - 4 } & 3.5 & \multicolumn{2}{|c}{} \\
\cline { 2 - 4 }
\end{tabular}

\subsection{Samples creation}

Before creating the 3-dimensional models, samples were firstly made through trial and error to find the best shape and size. This can be done by sketching. In this research, software AutoCAD from Autodesk was used as drawing media so that the measurement can be done 
precisely. Two IWF section steel beam types were the main samples of this research, namely IWF 150x75x5x7 and IWF 200x100x5.5x8.

There are at least six steps in the sample creation. First step is to cut the uniform beam into 2 sections with a circular shape. After that, those parts were separated and one of the parts was flipped horizontally. Then, the two parts of the separated beam were assumed to be re-jointed using a welding connection, while some unwanted parts were removed. In the end, the desired tapered castellated cantilever beam dimension was ready to be drawn as a 3D model. All of the steps can be seen in Figure 1.

IWF $150 \times 75 \times 5 \times 7$ has a height of $150 \mathrm{~mm}$ and IWF $200 \times 100 \times 5.5 \times 8$ has a height of 200 $\mathrm{mm}$. However, in this research, $15 \mathrm{~mm}$ from the top and bottom with a total of $30 \mathrm{~mm}$ was not modified due to the original curves from the fabrication process. From this action, it is known that the best height increase for IWF $150 \times 75 \times 5 \times 7$ was $230 \mathrm{~mm}$ and for IWF 200x100x5.5x8 was $318 \mathrm{~mm}$. After the dimensions were decided, all samples were drawn in $3 \mathrm{D}$ using FreeCAD to create a solid tetrahedron element. Opening spaces are the spaces between the holes' centres. The drawing process is depicted in Figure 2.

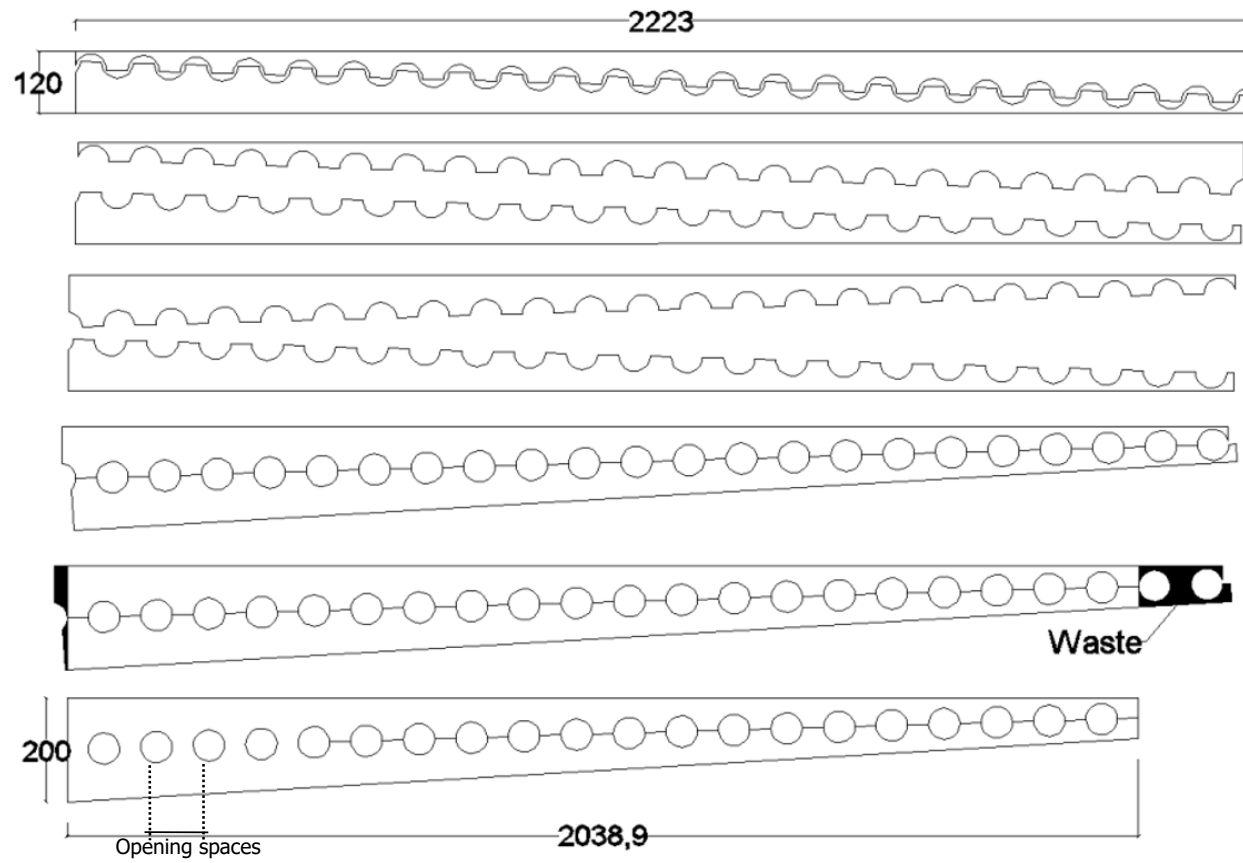

Fig. 1. Step by step process of sample creation. 


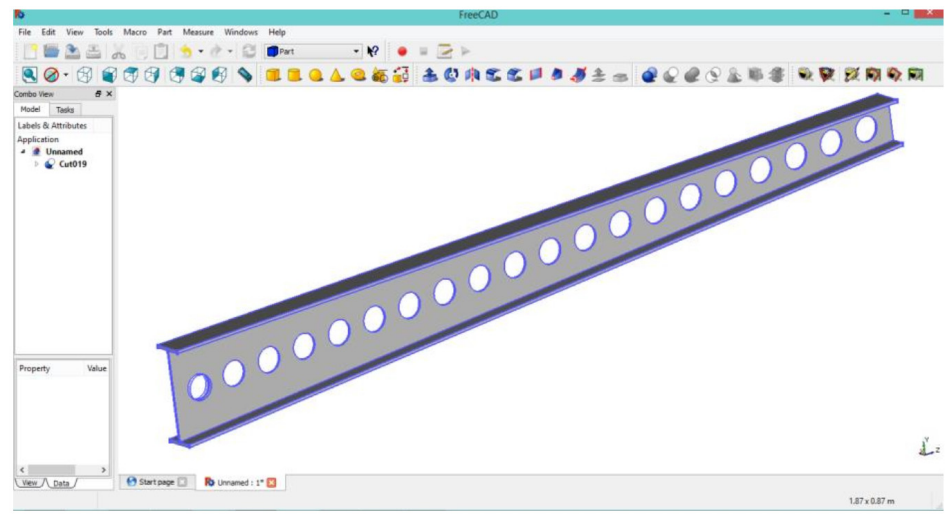

Fig. 2. Three-dimensional drawing of solid element.

\subsection{Analysis method}

All samples then were imported to LisaFEA to perform finite element analysis. The steel material properties have a yield strength $\left(f_{y}\right)$ of $400 \mathrm{MPa}$ and a Young's modulus $\left(E_{s}\right)$ of $200,000 \mathrm{MPa}$. The Von Mises yield criterion was used to retrieve the stress and displacement from analysis. Moreover, the given load was limited to just under the yield strength. The given loads for all samples with IWF $150 \times 75 \times 5 \times 7$ are 3.7 tonnes, 3 tonnes, 2.5 tonnes, and 2.1 tonnes respectively for a span length of $2.5 \mathrm{~m}, 3 \mathrm{~m}$, and $3.5 \mathrm{~m}$; while with IWF $200 \times 100 \times 5.5 \times 8$, the loads are 7.1 tonnes, 5.6 tonnes, 5 tonnes, and 4.5 tonnes.

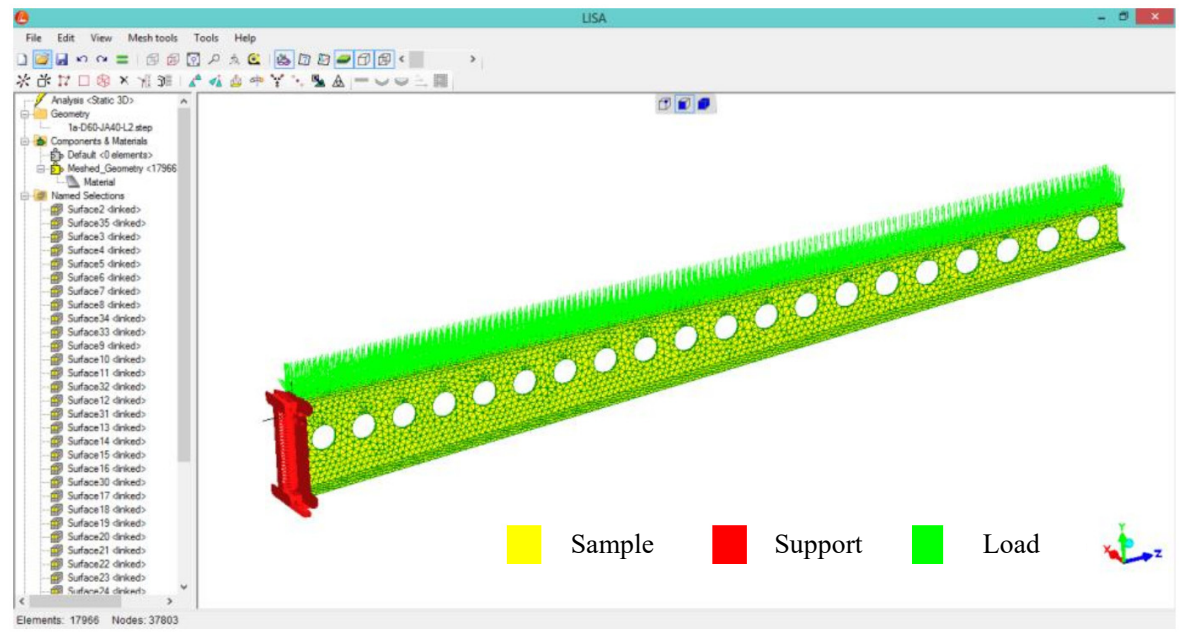

Fig. 3. Linear numerical analyses performed by LisaFEA software.

\section{Result and discussion}

\subsection{Convergence analysis}

The convergence analysis was performed to understand how much mesh should be implemented to all samples so that the expected significance is less than $5 \%$. All 
convergence test results are illustrated in Figure 4, which shows that 17,966 elements were chosen to create the meshing for this experiment.

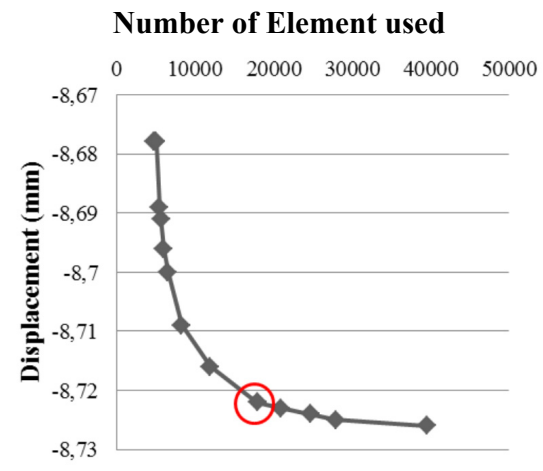

Fig. 4. Result of convergence analysis test.

\subsection{Stress and displacement result}

The finite element analysis that had been done produces the Von Mises stress and displacement of all samples. These two variables were used to compare the samples to each other. The results are shown in Figure 5 to Figure 12, with the figure on the left depicting the displacement result, and the right the stress result. Each figure represents the result for each span length and for its IWF cross section.
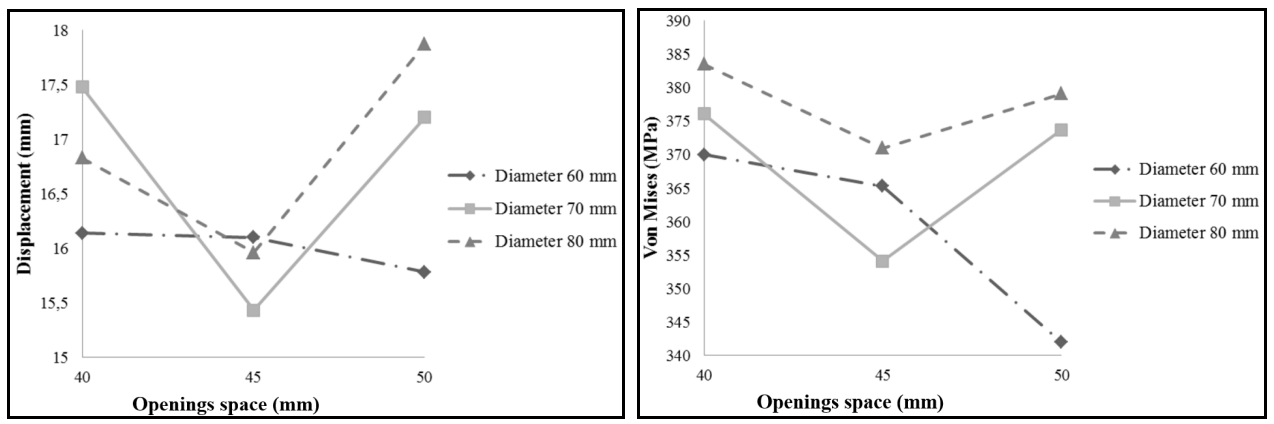

Fig. 5. Result of stress and displacement for IWF $150 \times 75 \times 5 \times 7$ with span length of $2 \mathrm{~m}$.
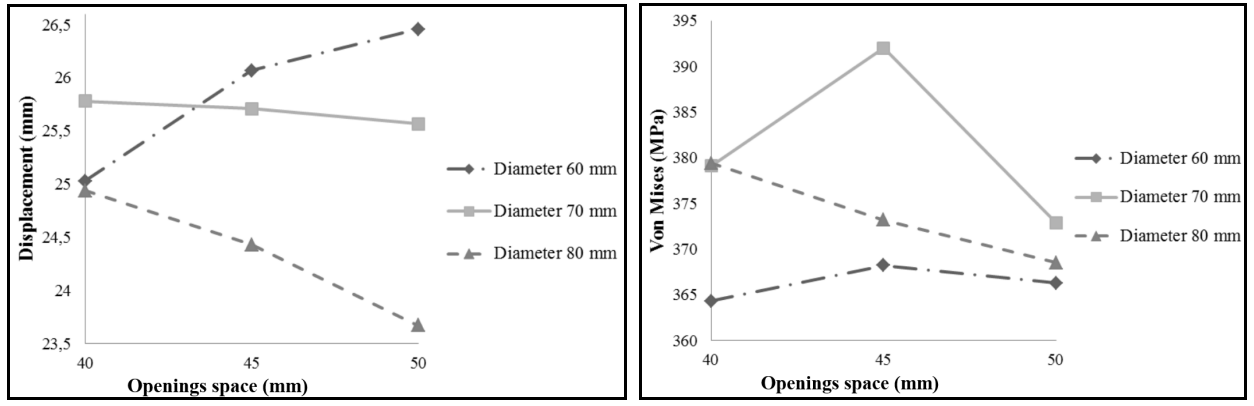

Fig. 6. Result of stress and displacement for IWF $150 \times 75 \times 5 \times 7$ with span length of $2.5 \mathrm{~m}$. 

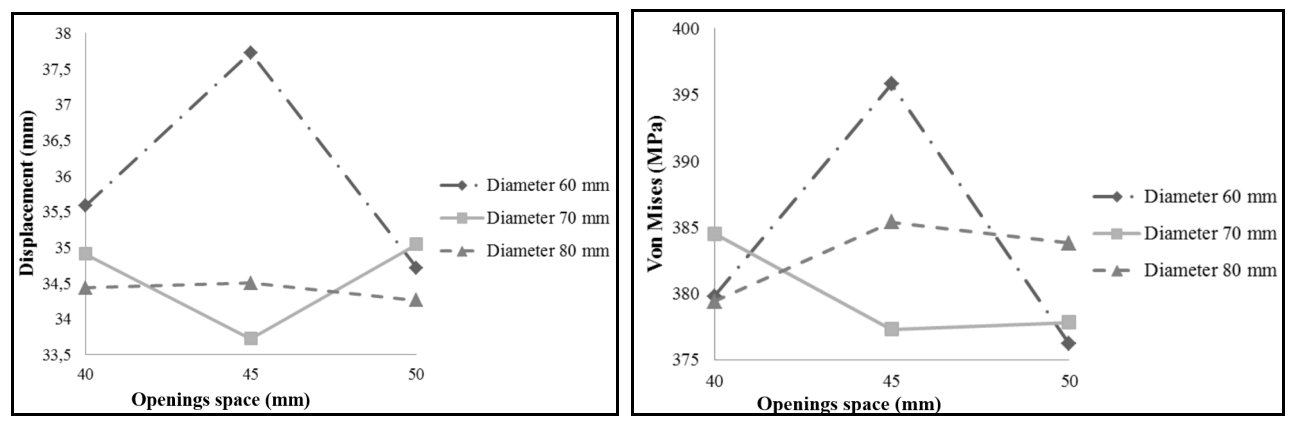

Fig. 7. Result of stress and displacement for IWF $150 \times 75 \times 5 \times 7$ with span length of $3 \mathrm{~m}$.
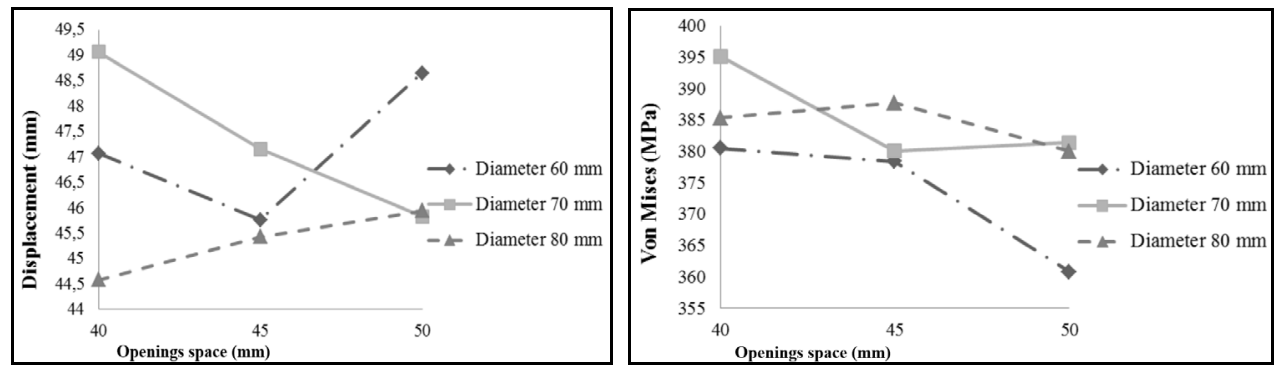

Fig. 8. Result of stress and displacement for IWF $150 \times 75 \times 5 \times 7$ with span length of $3.5 \mathrm{~m}$.
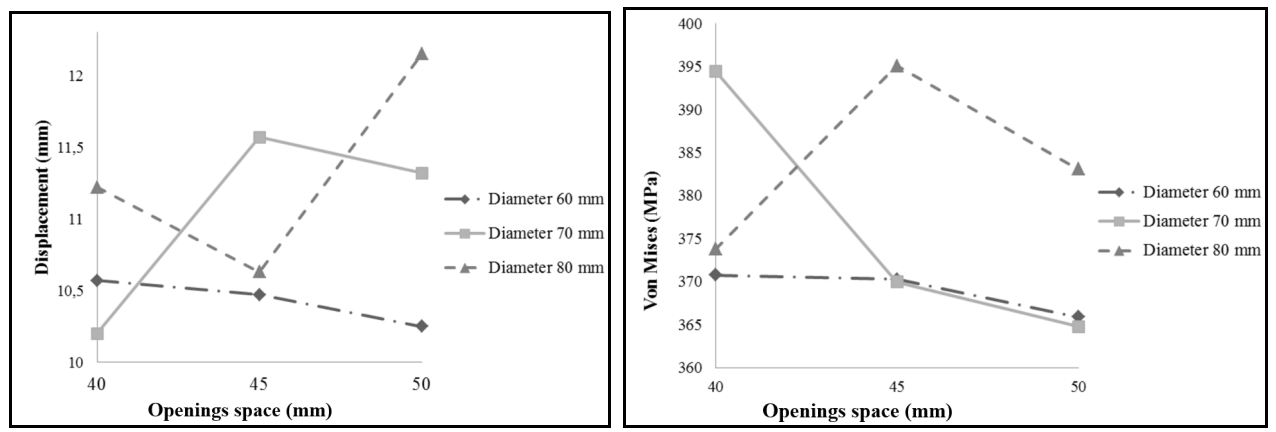

Fig. 9. Result of stress and displacement for IWF 200x100x5.5x8 with span length of $2 \mathrm{~m}$.
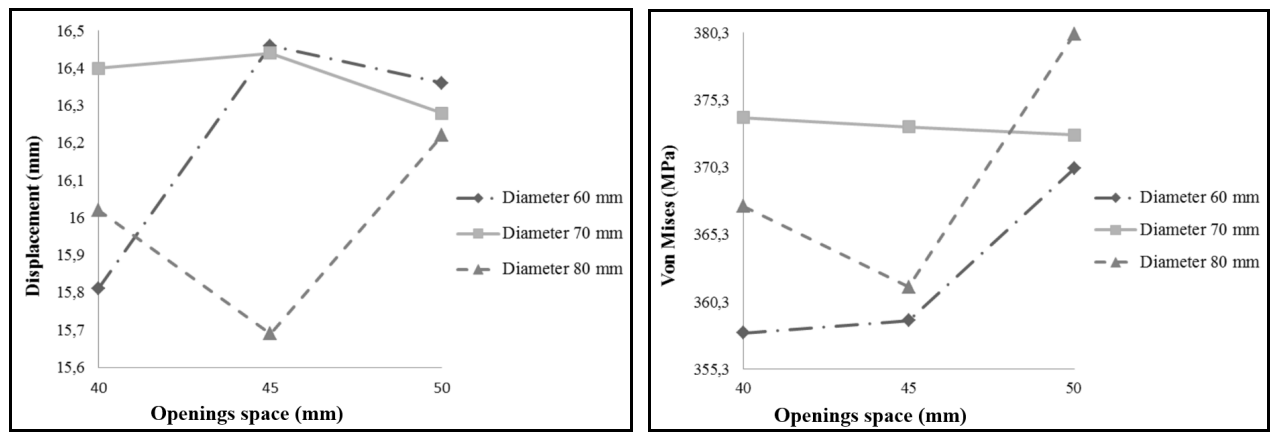

Fig. 10. Result of stress and displacement for IWF 200x100x5.5x8 with span length of $2.5 \mathrm{~m}$. 

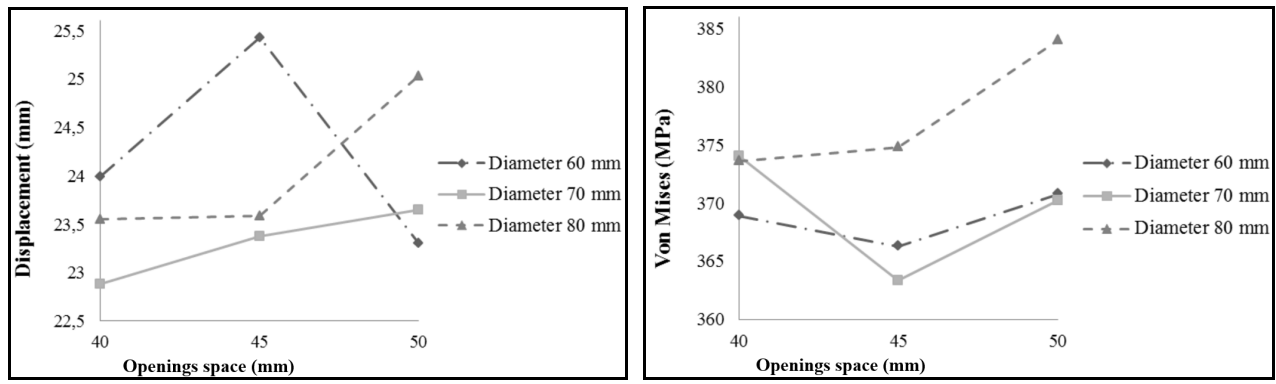

Fig. 11. Result of stress and displacement for IWF 200x100x5.5x8 with span length of $3 \mathrm{~m}$.
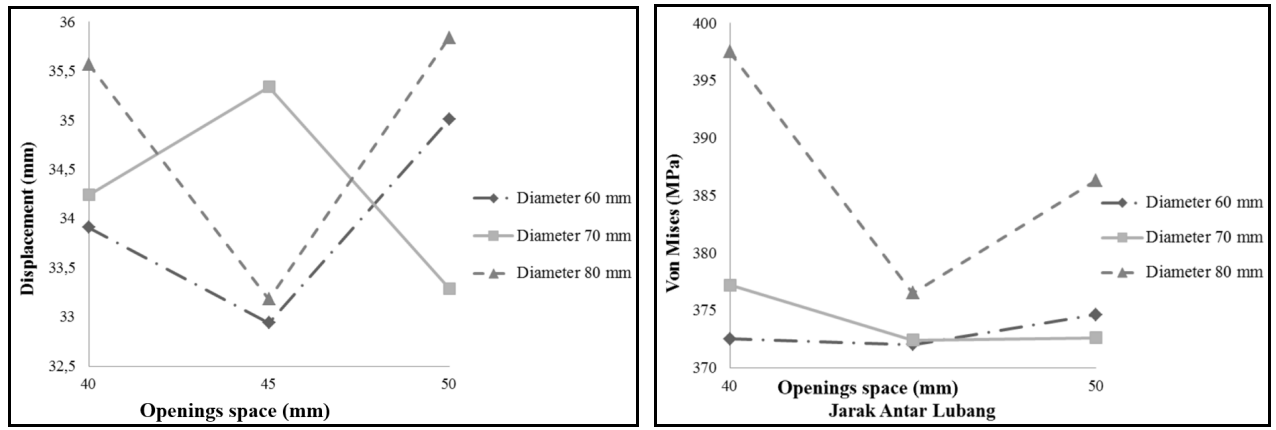

Fig. 12. Result of stress and displacement for IWF $200 \times 100 \times 5.5 \times 8$ with span length of $3.5 \mathrm{~m}$.

\section{Conclusion}

It is known that a tapered shape can be implemented as well as a castellated beam on cantilever supported beams. Moreover, both modifications have a positive impact to stress and displacement. The values of stress and displacement for each sample fluctuate and are unique. This might be caused by the variating number of openings resulting from the cutting in the beginning when creating the samples. The provided graphs can be useful for any practical structural engineers in the field wanting to determine the best option of cantilever steel beam to be used, depending on the desired smallest stress or smallest displacement for each length span.

\section{References}

1. M. Liu, K. Guo, P. Wang, C. Lou, Y. Zhang, Simplified method for prediction of elastic-plastic buckling strength of web-post panel castellated steel beams, Steel and Composite Structures, 25, 6, pp. 671-684 (2017)

2. H.A. Sarvestani, Cyclic behavior of hexagonal castellated beams in steel momentresisting frames with post-tensioned connections, Structures, Elsevier, 11, pp. 121-134 (2017)

3. A. Kaveh, M.H. Ghafari, Optimum design of castellated beams: Effects of composite action and semi-rigid connections, Scientia Iranica, 25, 1, pp.162-173 (2018)

4. T.I. Maulana, I. Satyarno, Flexural Behaviour of Modified Composite Mortar Castellated Beam with Rebar Steel Diagonal Connection under Cyclic Loading (Universitas Gadjah Mada, Yogyakarta, 2016) 
5. F. Erdal, S. Taş, O. Tunca, S. Carbaş, Effect of Random Number Sequences on The Optimum Design of Castellated Beams with Improved Harmony Search Method, International Journal of Engineering \& Applied Sciences, 8, 3, pp.25-39 (2016)

6. A.M. Jamadar, P.D. Kumbhar, Parametric study of castellated beam with circular and diamond shaped openings, International Research Journal of Engineering and Technology, 2, 2, pp.715-722 (2015)

7. L. Zhang, P. Wang, Simplified analysis method for catenary action of restrained cellular steel beams at elevated temperature considering strain reversal. Fire Safety Journal, 95, pp.145-159 (2018)

8. S. Durif, A. Bouchair, O. Vassart, Experimental and numerical investigation on webpost specimen from cellular beams with sinusoidal openings. Engineering Structures, 59, pp.587-598 (2014)

9. F. De'nan, H. Hasan, M. Mahzuz, Behaviour of the Beam to Column Connection for Tapered Steel Section with Perforation. Engineering Heritage Journal, 1,1 pp. 41-44 (2017)

10. M. Akbarzade, A. Farshidianfar, Nonlinear dynamic analysis of an elastically restrained cantilever tapered beam, Journal of Applied Mechanics and Technical Physics, 58, 3, pp. 556-565 (2017)

11. S.T. Dennis, K.W. Jones, Flexural-torsional vibration of a tapered C-section beam, Journal of Sound and Vibration, 393, pp. 401-414 (2017)

12. T.I. Maulana, Y.A. Harsoyo, F. Monika, Analysis of Stress and Deformation of Cantilever Steel Beam T Section and Half IWF Section using Finite Element Method, International Conference on Engineering and Applied Science University of Muhammadiyah Purwokerto (The 1st InCEAS 2016), pp. 68-74 (2016)

13. T.I. Maulana, B. Soebandono, B.S. Jagad, H. Prayuda, Stress and deformation analysis of tapered cantilever castellated beam using numerical method, IOP Conference Series: Material Science and Engineering, 352, 012029, pp. 1-5 (2018) 